\title{
Da Diplomacia das Canhoneiras às Alternativas Híbridas de Cooperação no Espaço Oceânico: Uma Reflexão Crítica sobre a Mobilização Internacional contra a Pirataria Marítima
}

\author{
From Gunboat Diplomacy to Hybrid Alternatives of \\ Cooperation in the Ocean Space: A Critical View on the \\ International Mobilization against Maritime Piracy
}

Gilberto Carvalho Oliveira*

\section{Resumo}

Com base no caso da pirataria nas costas da Somália e de algumas mobilizações não oficiais de comunidades costeiras contra o problema, o artigo pretende mostrar como uma combinação de iniciativas informais da esfera local com os mecanismos formais de intervenção internacional podem levar a uma abordagem diplomática alternativa - designada pela expressão "abordagem híbrida à pirataria" - capaz de produzir iniciativas que não se limitem à diplomacia coerciva que até o momento prevalece na resposta dominante dada ao problema.

Palavras-chave: Diplomacia informal, Governança global, Pirataria, Segurança marítima, Somália.

\section{Abstract}

Based on the case of piracy off the coast of Somalia and some coastal communities' unofficial mobilizations against the problem, the article aims to show how a combination of informal initiatives of the local sphere with international mechanisms of intervention can lead to an alternative diplomatic approach - designated by the term "hybrid approach to piracy" - able to produce initiatives that are not limited to the coercive diplomacy which, until now, prevails in the dominant response to the problem.

Keywords: Global governance, Informal diplomacy, Maritime security, Piracy, Somalia.

\footnotetext{
* Doutor em Relações Internacionais (Universidade de Coimbra, Portugal). Professor-Adjunto da Universidade Federal do Rio de Janeiro (UFRJ).
} 


\section{Introdução}

Este artigo parte da observação de que o ressurgimento da pirataria nas últimas duas décadas, emblematicamente ilustrado pela onda de sequestros a navios ao largo da costa somali, tem produzido um conjunto de medidas regulatórias diplomáticas - resoluções, normas, diretrizes e planos de contenção da pirataria forjados principalmente no Conselho de Segurança das Nações Unidas (CSNU), na Organização Marítima Internacional (IMO), nos Estados Unidos da América (EUA) e na União Europeia (EU) - e um conjunto de medidas militarizadas - intervenções navais internacionais no mar territorial da Somália, criação de corredores de segurança, bombardeios aéreos nas praias somalis, embarque de guardas armadas nos navios mercantes -, o que mostra que a mobilização internacional para gerir o problema tem sido articulada principalmente dentro de uma moldura coerciva.

Pode-se notar, dentro desse contexto, que esse conjunto de medidas diplomáticas e militares refletem um processo bem-sucedido de securitização da pirataria que faz com que a mobilização internacional para gerir o problema seja invariavelmente equacionada por meio do poder naval, reproduzindo, de certa forma, a lógica racionalista da "diplomacia da canhoneira", isto é, a clássica fórmula da dissuasão através da demonstração e uso limitado da força naval pelos Estados. A principal fragilidade dessa abordagem, conforme se pretende mostrar no artigo, é que essa racionalidade dissuasória pode não ser eficaz contra atores não governamentais, movidos por interesses econômicos privados e apoiados por uma rede local de autoridade e proteção que se nutre dos benefícios funcionais gerados pelos recursos provenientes da atividade de sequestro a navios. Em consequência, o máximo que essa "diplomacia da canhoneira" consegue produzir em termos de governança da segurança no espaço oceânico são equilíbrios instáveis, através da contenção das manifestações diretas da pirataria no mar, sem que as raízes do problema sejam transformadas de uma forma abrangente e sustentável.

Adotando uma perspectiva construtivista social sobre a transformação de conflitos, o argumento central a ser desenvolvido no artigo é que um enquadramento alternativo - que leve em conta os atores não estatais, as raízes sociais do problema dentro da Somália, os benefícios funcionais gerados pela pirataria e as necessidades concretas de segurança e desenvolvimento das comunidades costeiras diretamente afetadas pela pirataria - pode fazer emergir relações diplomáticas não convencionais, híbridas e em microescala, capazes de valorizar as dimensões "ideacionais" da questão, legitimar as instâncias costumeiras de autoridade e governança e valorizar estratégias e mobilizações locais, produzindo formas mais pacíficas, pluralistas, criativas e sustentáveis de enfrentar o problema.

Desse modo, através de uma breve revisão do debate sobre o papel das vias diplomáticas paralelas no contexto dos conflitos persistentes (primeira seção), da constatação das limitações da atual resposta securitizada dada ao problema (segunda seção), da análise das características peculiares da governança local na Somália (terceira seção) e do exame de quatro casos que mostram as potencialidades transformativas existentes dentro das comunidades locais diretamente afetadas pela pirataria (quarta seção), o artigo pretende mostrar como uma combinação das potencialidades locais com os mecanismos formais de ajuda internacional podem levar a uma abordagem alternativa - designada pela expressão "abordagem híbrida 
à pirataria" - capaz de produzir formas mais colaborativas, criativas e emancipatórias de governança que possam ir além da "diplomacia das canhoneiras" que até o momento prevalece na resposta dominante dada ao problema (quinta seção).

\section{Os Conflitos Persistentes e as Limitações da Diplomacia Convencional}

Diversos acadêmicos e praticantes envolvidos com a transformação de conflitos - vista como uma abordagem particular dentro do campo mais abrangente da Resolução de Conflitos - compartilham um ponto de vista comum sobre a complexidade dos conflitos contemporâneos e sobre a necessidade de ferramentas alternativas de transformação social que complementem os mecanismos tradicionais de gestão e resolução. Na base desse ponto de vista comum está a assunção de que as medidas coercivas militarizadas e as técnicas convencionais de negociação e mediação da diplomacia oficial são inadequadas ou insuficientes para lidar com as clivagens mais profundas que perduram por longos períodos nos chamados conflitos "intratáveis" ou "persistentes" (intractable conflicts ou protracted conflicts).

Esse tipo de conflito - que ganha visibilidade principalmente a partir dos estudos de Edward Azar $(1985,1990)$ e de outros estudiosos como Cohen e Azar (1981), Kriesberg, Terrell e Northrup (1989) e Kumar (1987) - caracteriza-se por uma multiplicidade de atores e questões, por oscilações na intensidade e na frequência dos confrontos e pela ausência de um ciclo claro de gênese, progressão, redução e terminação, o que acaba por prolongar o conflito indefinidamente, muitas vezes por décadas. Essas características produzem uma inversão na percepção dos grupos envolvidos no conflito que, em vez da vitória ou do estabelecimento de um acordo de paz, passam a ver na continuidade da guerra o seu objetivo maior (AZAR, 2003, p. 16). No seguimento desse debate, autores como Kaldor (1999), Keen (1998) e Reno (1999) observam que as tradicionais "guerras racionais clausewitzianas" cedem espaço, na conflitualidade observada a partir dos anos 1990, às chamadas "novas guerras": uma profusão de grupos militares e civis, movidos por uma mescla de interesses políticos e privados, que instrumentalizam a violência armada, não raras vezes para extrair vantagens econômicas pessoais, inclusive através de atividades criminosas (KALDOR, 1999, p. 102-110). A partir daí, diversos autores passam a chamar a atenção para o papel central das agendas econômicas na perpetuação dos conflitos armados contemporâneos (COLLIER e HOEFFLER, 1998; BERDAL e MALONE, 2000; COLLIER, 2000; KEEN, 2000; RENO, 2000; BALLENTINE e SHERMAN, 2003; PUGH e COOPER, 2004; DUFFIELD, 2000, 2001, 2007).

Perante esse quadro - onde uma mistura complexa de atores governamentais e não governamentais, agendas econômicas paralelas e profundas divisões étnicas, culturais e religiosas tornam o conflito pouco permeável aos mecanismos convencionais de resolução -, torna-se urgente pensar em formas alternativas de ação diplomática capazes de lidar com os aspectos que geralmente fogem das dinâmicas operacionais da diplomacia formal. Dentro do debate sobre essas formas alternativas de diplomacia, duas contribuições são cruciais. A primeira provém do trabalho do ex-diplomata americano Joseph Montville que, desde o início da década de 1980, tem refletido sobre o que ele chama de "diplomacia de segunda via" 
(second track diplomacy ou track two diplomacy): uma forma de interação não oficial e informal entre membros de grupos ou nações adversárias com o objetivo de desenvolver estratégias, influenciar a opinião pública e mobilizar recursos humanos e materiais que possam ajudar a resolver os seus conflitos (MONTVILLE, 1991, p. 162). Para Montville, a diplomacia de segunda via não deve ser vista como um mecanismo autônomo, mas sim como um trabalho complementar aos esforços oficiais da diplomacia de primeira via, sendo particularmente útil na busca de soluções que contribuam para satisfazer as necessidades básicas de segurança e estima das partes em luta, criar nas comunidades em conflito um ambiente receptivo à busca da paz e promover incentivos econômicos que possam reforçar os processos políticos e psicológicos de resolução de conflitos (1991, p. 162-164). A segunda contribuição-chave dentro desse debate deriva do conceito de "diplomacia de múltiplas vias" (multi-track diplomacy), proposto inicialmente pelo ex-diplomata americano John McDonald e subsequentemente desenvolvido em conjunto com Louise Diamond (1996). Indo além da diplomacia de duas vias, a expansão conceptual proposta por esses autores passa a incluir nove vias, cada uma relacionada a um setor específico da sociedade capaz de contribuir para a mitigação ou a resolução dos conflitos: governo, ONG, setor de negócios, cidadãos, pesquisa e educação, ativismo pacifista e ambiental, religião, fundações filantrópicas e mídia.

O que é crucial perceber, para os propósitos deste artigo, é que o legado tradicional da resolução de conflitos através de meios militares, diplomáticos e legais - incorporado à mentalidade coletiva da maioria das sociedades - já não consegue lidar de uma forma consistente com o amplo espectro de agentes e questões que moldam o tipo de violência organizada que vigora no contexto dos conflitos persistentes e intratáveis. Há, entre os autores aqui mencionados, uma clara percepção dos limites da diplomacia convencional dentro desses contextos. É essa base conceptual que permite defender, neste artigo, a busca de novas formas de cooperação e de ação diplomática alternativa que contribuam para transformar a economia política da pirataria dentro do contexto particular que marca o conflito intratável que se prolonga na Somália há quase três décadas. Nesse contexto de intratabilidade, marcado por uma sociedade altamente fragmentada, historicamente avessa à ideia do Estado central, fortemente leal às instâncias governativas locais e pouco permeável às iniciativas de intervenção internacional, torna-se premente expandir os mecanismos de intervenção e cooperação para além dos quadros e modelos padronizados da ação estatal.

\section{"Guerra contra a Pirataria"}

Se até meados dos anos 2000 a pirataria marítima não era sequer mencionada ou classificada como ameaça nos documentos de alto nível das Nações Unidas, os últimos anos da década testemunharam uma mudança radical desse quadro. Em 2008, o CSNU emitiu um conjunto de resoluções, declarando que a crescente onda de ataques de piratas ao largo da costa da Somália agravava a situação naquele país, o que constituía uma "ameaça à paz e à segurança internacionais". Desse modo, agindo sob o Capítulo VII da Carta das Nações Unidas, o CSNU convocou os Estados e organizações regionais dotados de capacidades navais (navios 
de guerra e aeronaves militares) para intervirem na região, inclusive no mar territorial e em terra na Somália, a fim de combater a pirataria na região. Embora algumas indicações de uma abordagem mais abrangente pudessem ser encontradas nessas resoluções, mencionando a necessidade de definir medidas de autoproteção dos navios mercantes e rastrear as ligações financeiras da pirataria em escala global, o ponto crucial a destacar era o seu foco no uso da força: as resoluções definiam não só medidas para reprimir a pirataria através do emprego de forças navais e aeronavais, mas também a ruptura e o desmantelamento das bases da pirataria em terra (OLIVEIRA, 2013a, 2013b).

As pressões diplomáticas dos EUA, conduzidas pela Secretária de Estado Condoleezza Rice junto às demais representações diplomáticas do CSNU nos últimos momentos do governo Bush, que resultaram na provação da resolução 1851 de 2008, são exemplares no sentido de mostrar os esforços de securitização da pirataria dentro do mais alto nível de decisão sobre as questões de segurança internacional (OLIVEIRA, 2015, p. 126). Essa resolução, a mais robusta das quatro resoluções contra a pirataria aprovadas em 2008, mostra claramente uma ambiguidade na abordagem ao problema: embora a resolução configure o pirata como criminoso e não como combatente - e, por esta razão, dotado do direito à defesa em tribunais de justiça -, as provisões da resolução dão margem para a entrada de aeronaves no espaço aéreo somali com o propósito de bombardear as bases da pirataria em terra. Isso configura um grau de letalidade no uso da força que não parece proporcional ao tipo de tratamento normalmente dado às típicas questões de criminalidade (HEINZE, 2013, p. 56).

Esse processo de securitização da pirataria somali, estudado de forma pormenorizada por Oliveira $(2015,2013 b)$, produziu uma série de efeitos que já se podiam notar no final de 2008 e início de 2009: diversos Estados (Japão, China, Rússia, Índia, Malásia, Coreia do Sul, Arábia Saudita, Irão e lémen) e três coligações marítimas multinacionais (uma liderada pelos EUA, outra liderada pela UE e uma terceira liderada pela OTAN) deslocaram seus navios de guerra e aeronaves militares para as águas da região. Hoje, aproximadamente trinta Estados encontramse envolvidos no combate à pirataria somali, não só no patrulhamento do Índico ocidental, mas principalmente na proteção do corredor de trânsito estabelecido no Golfo de Áden, denominado Corredor de Trânsito Internacionalmente Recomendado (Internationally Recommended Transit (orridor), por onde os navios mercantes podem navegar protegidos pelas forças navais das três coalizões multinacionais que operam na região. Essa mobilização internacional envolve, ainda, a participação da Organização Marítima Internacional e de outras agências especializadas da ONU, principalmente o Escritório das Nações Unidas sobre Drogas e Crime, que coordena capacitação jurídica e a instalação de prisões na Somália e em alguns Estados vizinhos. Para além disto, foi estabelecido um mecanismo diplomático de caráter consultivo no âmbito da ONU, integrado por cerca de sessenta países e vinte organizações governamentais e não governamentais, denominado Grupo de Contato contra a Pirataria ao Largo da Costa da Somália, com o propósito de propor recomendações em cinco áreas: coordenação dos esforços militares no combate à pirataria; promoção da infraestrutura jurídica necessária à punição dos piratas; fortalecimento dos mecanismos de autoproteção dos navios mercantes; promoção de uma campanha educativa e de divulgação regional sobre os perigos colocados pela pirataria; e identificação e desmantelamento das redes financeiras envolvidas na pirataria. 0 mais recente 
desenvolvimento nesse esforço internacional, estimulado principalmente pelos EUA e pelo Reino Unido e provisoriamente regulamentado pela Organização Marítima Internacional, é o emprego de empresas privadas de segurança marítima e o uso de armas a bordo dos navios mercantes que transitam nas águas do Índico ocidental, o que acrescenta mais um degrau na tendência de privatização da segurança que já tem sido observada, há algum tempo, nas ações de treinamento e no desempenho das tarefas de policiamento observadas nas guerras do Afeganistão e do Iraque (para um panorama abrangente dessa mobilização internacional, ver: HOMAN e KAMERLING, 2010; MURPHY, 2011; HAYWOOD e SPIVAK, 2012; BUEGER e STOCKBRUEGGER, 2013; OLIVEIRA, 2013a, 2013b).

O que é importante notar, conforme conclui Oliveira com base na análise dessa mobilização internacional contra a pirataria, é que os seus resultados não foram muito além da criação de espaços e corredores protegidos por forças navais internacionais e guardas armadas privadas, bem como do estabelecimento de uma infraestrutura rudimentar de julgamento e punição na Somália e em alguns Estados regionais com o objetivo de livrar os Estados ocidentais da responsabilidade de arcar com os processos penais dos suspeitos de pirataria capturados em suas operações (2013a, p. 15). O problema dessa estratégia de contenção, sob as lentes críticas aqui adotadas, não está apenas no custo elevado dessa extraordinária mobilização naval, mas está principalmente nos seus resultados parciais, na sua forte dependência das forças militares estrangeiras e no seu baixo impacto transformativo sobre as raizes do problema, o que torna questionável a sua sustentabilidade num horizonte de tempo mais prolongado. Ainda que se possa comemorar uma redução acentuada na quantidade de sequestros bem-sucedidos, principalmente a partir de 2013, não se pode ignorar a resiliência da pirataria, ou seja, a sua capacidade de adaptação e diversificação de atividades e conexões com outras economias de guerra na Somália para contornar as pressões impostas pela intervenção naval internacional. Não se pode igualmente ignorar que a situação na Somália, particularmente em relação à capacitação do seu embrião de governo central para assumir a estratégia de contenção da pirataria, não parece ter evoluído substancialmente desde o início da mobilização internacional em 2008 (OLIVEIRA, 2013a, p. 12-13).

Perante esse diagnóstico, um aspecto parece crucial: a gestão do problema da pirataria somali dentro de uma lógica emergencial e coerciva, resultante dos esforços diplomáticos internacionais de regulação e da resposta preponderantemente militarizada, imposta de "cima para baixo", sustentada por forças navais estrangeiras e por guardas armadas privadas embarcadas nos navios mercantes, não tem sido nem eficiente, na medida em que não altera as condições locais que alimentam a economia política da pirataria e não consegue evitar que os grupos de piratas continuem a adaptar o seu modus operandi para contornar a pressão militar internacional, e nem eficaz, na medida em que os seus resultados são parciais, não conseguindo alcançar o propósito definido pelo CSNU no sentido de solucionar o problema da pirataria somali de uma forma "completa" (S/RES/1846/2008, p. 2) e "duradoura" (S/RES/1897/2009: 2). Isto sugere a necessidade de examinar novas formas de mobilização, mais próximas do contexto particular das comunidades locais diretamente afetadas pela pirataria, a fim de vislumbrar alternativas que possam contribuir para a transformação da economia política de uma forma sustentável. 


\section{Aspectos da Governança Local na Somália}

Existem algumas condições sociais enraizadas na Somália - tais como o sistema de clãs, a religião e o direito costumeiro - que influenciam significativamente o dia a dia das pessoas nas comunidades locais. Entre essas condições, o sistema de clãs destaca-se por ser a forma predominante de organização social no país, constituindo um complexo mosaico de linhagens genealógicas, segmentado, fluído, flexível e dinâmico (ELMI, 2010, p. 47; MENKHAUS, 2010, p. 88-89), que virtualmente inclui todos os somalis e os conecta, em sua origem mais remota, a um ancestral comum: Aqiil Abu Taalib, filho de um tio/sogro do Profeta Maomé. Os clãs e suas subdivisões em subclãs e sub-subclãs fornecem, portanto, não só uma identidade histórica compartilhada que se liga diretamente às origens do Islã, mas também um mapa mental que, ainda hoje, permite que cada somali se situe numa árvore genealógica particular e identifique a sua proximidade ou distância em relação aos demais ramos da árvore e às outras linhagens (CASSANELLI, 2010, p. 54). Ainda que essas linhagens tenham sido transmitidas dentro da tradição oral da sociedade tipicamente nômade/pastoril da Somália - e, como tal, sujeita a distorções, lembranças seletivas, esquecimentos e manipulações (CASSANELLI, 2010, p. 55) e sejam consideradas por alguns estudiosos mais como um constructo metafórico e simbólico, inventado ou imaginado, do que como uma representação fiel baseada em laços de sangue e de descendência concretos (ABBINK, 2009, p. 3; ELMI, 2010, p. 30; MENKHAUS, 2010, p. 88-89), elas continuam a determinar a maneira como a maioria dos somalis reconhecem uns aos outros nas esferas pública e privada, o modo como eles manifestam a sua solidariedade, salvaguardam o seu direito à vida e à propriedade, organizam os seus negócios, competem por recursos e estruturam a sua vida política (ELMI, 2010, p. 32-34). Desse modo, ainda que se reconheça o caráter fluído, flexível e dinâmico desse constructo social identitário, o "clãnismo" permanece como a força mais potente dentro da política e da sociedade somali (ADAN, 2010, p. 133).

O Islã é outro traço profundamente enraizado no dia a dia da sociedade somali. Seguindo a vertente sunita e orientando as suas práticas religiosas com base nas tradições sufistas, os somalis adotam uma interpretação moderada da Sharia e dos códigos islâmicos de conduta (SANDSTROM, 2012, p. 133). Dentro desse contexto, o Islã tem sido geralmente separado da política na Somália: os líderes religiosos desempenham papéis tipicamente religiosos, tais como ensinar aos jovens os elementos da fé e o texto do Corão, conduzir cerimônias de casamento, mediar disputas matrimoniais e gerir assuntos de herança à luz da lei islâmica. Desse modo, mesmo que se observe na última década o surgimento de grupos islâmicos radicais no conflito civil da Somália (tais como Al Shabaab e Hisbul Islan), comprometidos com a implantação de um Estado Nacional Islâmico e favoráveis à glorificação da violência, inclusive através de ataques suicidas, alguns analistas têm chamado a atenção para o fato dessas posições radicais refletirem mais uma influência estrangeira, uma espécie de "jihadismo" importado, do que uma força sustentável e historicamente enraizada na sociedade somali (ADAN, 2010, p. 132). A maioria da população do país, grande parte dela vivendo nas comunidades pastoris e agropastoris do interior, ligam-se igualmente ao direito islâmico (Sharia) e ao direito tradicional (Xeer), resistindo, em geral, às tentativas de imposição de leis fundamentalistas do Islã sobre as suas tradições e costumes antigos e sobre alguns hábitos mais modernos, tais como o 
direito das mulheres à escola, a liberdade dos comerciantes na condução dos seus negócios, a liberdade dos jovens no acesso a filmes, televisão, desporto, computadores e telefones celulares (ADAN, 2010, p. 132).

O terceiro aspecto crucial, com grande impacto social no dia a dia dos somalis, é o direito costumeiro (Xeer) e o princípio da "retribuição" ou "compensação" (diya). O Xeer diz respeito às leis tradicionais relativas ao casamento, à guerra, à terra, aos recursos naturais e outras questões práticas, e fornece, desse modo, o quadro legal costumeiro que orienta as deliberações e decisões dos anciãos (elders) quanto às relações entre clãs, subclãs e sub-subclãs. 0 diya, por sua vez, define a compensação (uma espécie de pagamento) pela morte, ferimento, má conduta ou atos de violência provocados entre membros de diferentes grupos (LITLLE, 2003, p. 154). É importante notar, como destaca Sandstrom (2012, p. 134), que essa instituição do direito costumeiro somali não se insere numa relação entre indivíduos, mas entre grupos; assim, para fazer jus a uma reparação desse tipo, o indivíduo é dependente de um "grupo pagante de diya", cujos membros são contratualmente e moralmente obrigados a assumir uma responsabilidade coletiva. Esse mecanismo contribui para que as pessoas nas comunidades locais somalis, em vez de agirem individualmente, sejam fortemente motivadas a manterem suas conexões aos "grupos pagantes de diya" (em geral organizados dentro dos clãs, subclãs e sub-subclãs); essa conexão é importante não só porque esse mecanismo de reparação funciona como uma espécie de seguro informal contra danos sofridos ou provocados, mas também porque, no nivel das comunidades somalis, existe pouco espaço para qualquer individualidade que seja desconectada das preocupações do grupo (2012, p. 134-135).

Apesar dos esforços da ditadura de Siyad Barre nos anos 1970 e 1980 no sentido de reprimir as expressões públicas das identidades de clãs e das instituições do direito costumeiro, a fim de impor formas modernas de governança inclusive nas comunidades mais distantes, o fato é que esses esforços não surtiram grande efeito: mesmo sob a repressão dos administradores e comitês do governo central implantados nas comunidades locais, o Xeer e os grupos de diya continuaram a operar. Com a guerra civil e o desaparecimento de qualquer resquício de autoridade central na Somália, essas instituições costumeiras voltaram com mais força. Nesse contexto, o compacto social formado pelo "clãnismo", Sharia, Xeer e diya exerceram, e continuam a exercer até o presente, uma função crucial na manutenção de um relativo grau de estabilidade no nivel das comunidades locais na Somália, especialmente na porção norte do país, onde os processos de reconciliação e paz ocorridos nos anos 1990 em Somaliland e Puntland foram conduzidos "de baixo para cima" com base nessas instâncias costumeiras de autoridade e governança locais.

Se, de um lado, o impacto social das instâncias costumeiras sobre o dia a dia dos somalis e o tipo de política informal em microescala que dai emerge têm sido sistematicamente invisibilizados e negligenciados nas iniciativas externas de construção da paz na Somália - sob o temor de que essas instâncias informais fragmentem os esforços de centralização do poder no Governo Federal da Somália - é interessante notar que essa dimensão governativa local não tem passado desapercebida dos especialistas em segurança. As observações de David Kilcullen (2010, p. 156), antropologista social, ex-oficial de infantaria do exército australiano e autor de um tratado de contrainsurgência, mostram uma clara percepção de que as instâncias costumeiras 
e a política informal em microescala, típicas da esfera local na Somália, têm sido efetivas nos esforços de estabilização e reconciliação em grande parte do país, ao contrário das iniciativas apoiadas pela comunidade internacional conduzidas no Sul. Peter Pham, outro especialista em segurança focado nas questões do Médio Oriente e África, dá indicações de que alguns atores internacionais, como os EUA e a União Africana, começam a perceber a relevância do papel desses arranjos de governança locais na estabilização da Somália (2011, p. 146-147).

É preciso, porém, ter uma noção da real dimensão desse interesse na esfera local somali. Nada indica que uma mudança significativa esteja em curso na estratégia internacional de construção da paz para a Somália: a abordagem internacional continua presa às questões de segurança e ao projeto de construção do Estado central, onde a política informal e as estruturas de governança costumeiras da esfera local não exercem qualquer protagonismo. O que os exemplos aqui mencionados realmente mostram é que essas instâncias locais só têm despertado a atenção externa como parte de estratégias de contrainsurgência que procuram instrumentalizar o conhecimento e os agentes locais em prol do cumprimento das missões dos principais atores de segurança internacionais, principalmente daqueles envolvidos na "guerra contra o terrorismo" e também nos esforços de combate à pirataria, conforme será ilustrado mais adiante.

Mas o fato realmente relevante em relação à esfera local na Somália, que parece crucial do ponto de vista transformativo, é que os processos informais de estabilização construídos "de baixo para cima", com base nas instâncias costumeiras de governança, têm conseguido produzir resultados mais efetivos na construção de um ambiente mais estável em diversas áreas da Somália do que os grandes processos "de cima para baixo" controlados pela comunidade internacional ao longo de mais de duas décadas de intervenções. Isto leva a supor - e aqui reside um ponto fundamental para os propósitos críticos desta análise - que as instâncias concretas de autoridade e governança nos níveis local e regional na Somália parecem ser potencialmente mais promissoras na transformação da economia política da pirataria do que o embrião de Estado central encastelado em Mogadício. Considerando essa possibilidade, duas questões tornam-se cruciais. Primeiro: quais são as potencialidades concretas da esfera local na transformação da economia política da pirataria somali? Segundo: até que ponto essas potencialidades da esfera local são suscetíveis a uma combinação com intervenções externas dentro de uma abordagem que vá além de uma mera estratégia de contrainsurgência?

\section{Potencial da Esfera Local na Transformação da Economia Política da Pirataria Somali}

Não se pode deixar de destacar que as instâncias de autoridade e governança costumeiras existentes na Somália se posicionam de uma forma ambígua em relação ao problema da pirataria. Ao mesmo tempo que elas podem funcionar como um mecanismo de proteção, fazendo "vista grossa" às atividades dos piratas e facilitando a sua impunidade, elas podem também dar respostas efetivas na contenção e na transformação da pirataria somali. Diversos analistas têm notado que o "clãnismo" é um fator sempre subjacente às dinâmicas da pirataria 
somali. Essa ligação da pirataria ao sistema de clãs explica-se, principalmente, em função da proteção. Isso fica claro nas entrevistas com diferentes piratas realizadas por Hansen (2009), onde se notam depoimentos do seguinte tipo: "os piratas dependem da proteção dos clãs". Ou então: "os clãs dão proteção aos piratas em troca de Qaaraan (uma espécie de taxa paga em dinheiro ou em rebanhos aos necessitados da comunidade); como os piratas geralmente pagam Qaaraan, torna-se difícil prender um pirata sem provocar a hostilidade do clã" (2009, p. 25-27). As entrevistas realizadas por Eichstaedt a piratas e negociadores de resgates confirmam essas taxas pagas pela pirataria somali às comunidades ou aos líderes dos clãs locais em troca de proteção (que podem passar de cem mil dólares apenas para obter o direito de manter o navio sequestrado nas águas da região durante as negociações de resgate) e acrescenta que eventuais conflitos gerados na pirataria, incluindo as mortes geradas nas habituais lutas dentro de um grupo ou entre deferentes grupos de piratas, são geralmente solucionados nas assembleias de anciãos através de reparações entre "grupos pagantes de diya" (2010, p. 57, 62).

Se, de um lado, esses aspectos tradicionais são mobilizados pela pirataria em troca de proteção, não se pode deixar de notar, de outro lado, que algumas respostas efetivas no controle da pirataria somali têm sido produzidas dentro dessas mesmas instâncias de autoridade e governança locais. 0 caso do governo da União das Cortes Islâmicas (Islamic Courts Union ICU), que desarticulou as mais importantes bases da pirataria em 2006, declarando a pirataria como uma violação à Sharia, é o primeiro exemplo a ser destacado. Formada por uma aliança de cortes religiosas, dotadas de milícias armadas e apoiadas por negociantes, políticos e líderes de clãs locais, a ICU tinha um projeto político islâmico preponderantemente moderado, apesar de uma ala jovem mais radical, cujo objetivo imediato era reagir pragmaticamente contra a coalizão de "senhores da guerra" que alimentavam a violência na capital e em grande parte da região centro-sul do país e substituir o cronicamente frágil embrião de governo central (Transitional Federal Covernment - TFG), percebido na Somália como um projeto estrangeiro sem qualquer legitimidade interna. Durante os sete meses em que se manteve no poder em 2006, a ICU foi capaz de prover, rapidamente, níveis elevados de estabilidade e razoável grau de serviços públicos básicos nas áreas cronicamente mais violentas do país, além de contar com um amplo apoio da população, dos negociantes e dos clãs locais em Mogadíscio e na região centro-sul da Somália. Nesse contexto, juntamente com as ações adotadas para desarticular a ação dos "senhores da guerra", a pirataria foi declarada uma violação aos princípios do Islão (haram), resultando na intervenção da ICU nas principais bases de piratas e na aplicação das leis da Sharia aos envolvidos nas atividades da pirataria. Como resultado, a atividade dos piratas foi reduzida praticamente a zero, até que a dissolução da ICU provocada pela invasão da Somália por tropas da Etiópia em dezembro de 2006 e o retorno do TFG ao poder sem qualquer capacidade real de controlar mais do que alguns poucos quarteirões de Mogadíscio abriram espaço para que as bases da pirataria voltassem a florescer, levando à situação que culminou em 2008 com a interferência do CSNU.

O segundo caso a destacar refere-se à Somaliland, que tem sido amplamente mencionada pelos analistas e estudiosos da Somália como uma região livre da pirataria. À exceção dos casos observados no litoral oriental de Sanaag - pertencente à Somaliland, mas contestada por Puntland, sem ser realmente controlada por nenhum dos dois protogovernos regionais - não 
se têm notícias de que as praias e os portos de Somaliland tenham sido utilizados para lançar ataques de piratas ou para abrigar navios sequestrados. O ponto crucial a observar em relação a esse facto é que a ausência de pirataria nas águas de Somaliland não resulta propriamente de ações repressivas no mar (embora o governo regional conte com uma pequena guarda-costeira), mas sim de medidas preventivas adotadas por suas comunidades litorâneas, envolvendo sociedade civil, os mecanismos de direito costumeiro e polícias comunitárias, que conseguem reagir aos rumores de formação de grupos de pirataria, desarticulando-os antes mesmo que eles se organizem e se lancem ao mar (HANSEN, 2009, p. 30). Portanto, o sucesso de Somaliland no controle da pirataria não está, conforme destaca Hansen, em suas capacidades navais e policiais (que são frágeis), mas sim no domínio e controle popular de amplas áreas do litoral, cujas comunidades conseguem, graças às instituições do direito costumeiro e ao policiamento informal, serem efetivas na imposição da lei e da ordem em seu domínio local.

Bandar Beyla, uma pobre cidade litorânea localizada praticamente no epicentro da pirataria em Puntland, no litoral nordeste da Somália, é outro caso a destacar. Nessa localidade, a mobilização da sociedade civil através de um forte trabalho educacional conduzido por uma organização local de mulheres e por um comitê antipirataria composto por anciãos, jovens, mulheres e autoridades locais tem conseguido desencorajar a adesão dos jovens à pirataria e impedir que grupos de piratas voltem a se estabelecer na região. A organização local de mulheres de Bandar Beyla, que opera desde 2004 sem qualquer apoio financeiro do governo de transição, do governo de Puntland e de instituições internacionais, funciona graças a contribuições da população local e de professoras voluntárias que conseguem prover a educação básica a aproximadamente 60 crianças (meninos e meninas) e a educação em diferentes disciplinas a cerca de 250 jovens estudantes do sexo feminino. 0 programa de esclarecimento contra a pirataria conduzido por essa organização, que abriga várias mães e viúvas de piratas que nunca regressaram de suas operações no mar, procura utilizar elementos valorizados na cultura tradicional local (como a música e a poesia oral), a fim de atingir os seguintes objetivos: informar a comunidade sobre os perigos da pirataria; conclamar a população local a não prestar o apoio logístico de que eles necessitam; afastar as mulheres jovens dos piratas; evitar que se formem laços de amizade entre os jovens da comunidade e os piratas; e disseminar mensagens que desestimulem a pirataria e encorajem o retorno de ex-piratas, bem como dos jovens em geral, às atividades de pesca. Para além do ativismo dessa organização de mulheres, o comitê antipirataria criou uma polícia composta de jovens da comunidade local, que procura impedir a formação de grupos de pirataria na região. O resultado desse conjunto de iniciativas é que Bandar Beyla tem conseguido evitar, desde 2011, que bases da pirataria voltem a se estabelecer em seu litoral (SOMALIA REPORT, 2012).

Eyl, outra famosa base de piratas em Puntland, que floresceu entre 2007 e 2009 ao ritmo de dezenas de sequestros a navios liderados por um dos piratas mais conhecidos da Somália, o legendário Boyah, tornou-se praticamente livre do problema a partir de 2010-2011 devido a uma estratégia de mobilização da comunidade local, liderada por anciãos e líderes religiosos, com o propósito de alterar o ambiente de aceitação à pirataria. Embora a economia de Eyl se tenha tornado dependente da pirataria, beneficiando-se dos lucros gerados pelo apoio logístico prestado às suas operações e dos gastos e investimentos pessoais de piratas enriquecidos, o 
sentimento da população alterou-se gradativamente devido à introdução de comportamentos considerados inaceitáveis dentro dos padrões religiosos e morais locais, como a prostituição, o uso de drogas e bebidas alcoólicas, o aumento da corrupção e o recrutamento de crianças para a pirataria. Eyl passou a ser palco de disputas violentas dentro dos clãs motivadas pela pirataria, tiroteios provocados por excesso de bebidas alcoólicas, violência entre grupos de piratas, muitas vezes provocando a morte ou ferimento de pessoas inocentes da cidade. Para além desse conjunto de problemas, a cidade testemunhou a falência de sua tradicional atividade econômica, a pesca, totalmente convertida para a pirataria. A fim de reagir contra esse estado de coisas, os anciãos uniram-se aos líderes religiosos da cidade, iniciando em 2010 um trabalho ativo de convencimento dos negociantes e da sociedade civil local no sentido de não aceitar o dinheiro proveniente dos piratas e de seus dependentes, declarado haram pelos líderes religiosos. O objetivo dessa estratégia era transformar a cidade num ambiente desfavorável à pirataria, negando os recursos que the são essenciais: recrutas, bens e serviços, e a "vista grossa" da comunidade durante os longos períodos em que os navios ficam fundeados próximos às praias aguardando as negociações de resgate. Essa resposta local - construída através de uma mescla das estruturas de autoridade tradicional, do sentimento religioso e moral e da mobilização da sociedade civil - criou uma frente de pressão que conseguiu reverter a (má) fama de "capital da pirataria" adquirida por Eyl, revitalizando a sua atividade econômica principal, a pesca, e mantendo a cidade praticamente livre de piratas desde 2010 (PELTON, 2012; WALJE, 2013).

Um aspeto crucial a destacar com base nesses casos é que, embora a pirataria somali tenha efeitos globais, o contexto particular dentro do qual ela emerge é altamente localizado. Longe de ser um fenômeno generalizado dentro da Somália, a pirataria opera a partir de poucas comunidades costeiras de Puntland e do litoral central da Somália das quais depende para existir: sem o apoio logístico prestado pelos negociantes dessas comunidades e sem a tolerância (mesmo que velada sob a forma de "vista grossa") das populações e das estruturas de autoridade e governança locais, a pirataria é uma atividade inviável. É importante notar que o que particulariza a pirataria somali é o sequestro e a manutenção de grandes navios mercantes com suas tripulações, durante períodos prolongados de cativeiro, fundeados próximos à costa e sob a vigilância permanente de piratas posicionados na praia, à espera de resgates pagos por quem quer que seja (seguradoras marítimas, companhias de navegação, Estados ou famílias dos membros das tripulações). Dentro desse modelo, os processos de negociação são longos, arrastando-se muitas vezes por mais de um ano, enquanto o navio sequestrado permanece ao largo, sob o olhar ostensivo de qualquer um que passe pela praia. A atividade dos piratas somalis, portanto, não é algo que possa ser camuflado dentro de pequenos canais, baías escondidas ou atrás de ilhas cobertas de vegetação - essas não são características do litoral somali. Isto faz das suas atividades algo até certo ponto compartilhado pelas comunidades que Ihes servem de base, não só durante a preparação das operações, mas principalmente durante o período em que o navio permanece ao largo aguardando o pagamento do resgate.

Desse modo, as respostas locais aqui ilustradas mostram duas descobertas fundamentais: a primeira é que as estruturas de apoio e a aceitação das comunidades são condições necessárias à existência da pirataria somali; a segunda é que essas condições são maleáveis, podendo ser transformadas de um sentido destrutivo para um sentido construtivo. Com base nessas 
descobertas, o compacto formado pelas lideranças religiosas, anciãos e sociedade civil é capaz de transformar, através do trabalho educativo, das manifestações culturais locais, da mobilização do direito costumeiro e religioso, da criação de atividades alternativas para os jovens e do policiamento local, a estrutura de autoridade e proteção que se beneficia da economia política da pirataria e permite o seu florescimento. Os exemplos de Bandar Beyla e Eyl, principalmente, mostram que até mesmo comunidades fortemente dependentes da pirataria são capazes de se tornarem livres do problema através da mobilização dessas instâncias locais. Portanto, o ponto crucial a notar com base nos casos aqui ilustrados é que, em vez de uma grande solução externamente controlada, imposta de "cima para baixo", dispendiosa e pouco sustentável, tal como a engendrada pela mobilização internacional orquestrada pelo CSNU - que serve mais aos objetivos de segurança próprios dos atores envolvidos do que à transformação das contradições sociais concretas que fazem a pirataria emergir (OLIVEIRA, 2013a, p. 13-14) - as pequenas respostas, forjadas "de baixo para cima" com o pleno domínio local, são formas alternativas de enfrentar o problema dentro de um quadro transformativo mais próximo e conectado ao contexto particular da pirataria somali. Embora envolvam estruturas de autoridade e governança indígenas, estranhas ou inaceitáveis aos olhos liberais ocidentais, essas pequenas mobilizações têm conseguido intervir em duas pré-condições fundamentais e necessárias à existência da pirataria somali (as estruturas de apoio logístico e a aceitação das comunidades que lhe servem de base), movendo-as de um sentido anteriormente destrutivo para um sentido construtivo que cria na comunidade um ambiente não propício à formação e manutenção dos grupos de piratas.

\section{Por uma Abordagem Híbrida à Pirataria Somali}

As práticas diplomáticas regulatórias voltadas para governança global da segurança marítima - conduzidas principalmente nos escritórios da Organização Marítima Internacional (Londres), Assembleia Geral da ONU e CSNU (Nova lorque) e, no caso particular da pirataria somali, conduzidas também no âmbito da estrutura ad hoc criada na ONU denominada Grupo de Contato contra a Pirataria ao Largo da Costa da Somália (BUEGER e STOCKBRUEGGER, 2013, p. 110-113) - têm servido basicamente para justificar e regular as medidas coercivas propostas nas resoluções contra a pirataria (intervenções militares no mar territorial e em terra na Somália, uso da força contra a pirataria, embarque de guardas armadas nos navios mercantes, construção de um aparato jurídico-carcerário na região). Mesmo quando essas instâncias diplomáticas adotam um discurso mais transformativo e menos centrado no uso da força, o seu foco é dirigido para o desenvolvimento do embrião de Estado central na Somália, na esperança de que o fortalecimento das capacidades de governo e participação política, de imposição da lei e da ordem, de uma economia de mercado e de mecanismos de justiça e respeito aos direitos humanos criem as condições necessárias para a erradicação da pirataria de um forma "completa" e "durável". O problema é que existe um abismo entre essa receita liberal e as condições concretas existentes para que se atinja esse "ponto de chegada". Assim, enquanto esse projeto liberal permanece "virtual", descolado da realidade concreta da Somália e com seus objetivos de desenvolvimento praticamente restritos no nível da retórica, são as medidas coercivas e a lógica 
securitária que realmente determinam a forma como os Estados se mobilizam para lidar com o problema da pirataria (OLIVEIRA, 2013a).

Por outro lado, o que as iniciativas locais destacadas na seção anterior revelam, e que parece crucial para o argumento aqui desenvolvido, é que a transformação deve partir da situação concreta e presente: dado o forte impacto social exercido pelas instituições costumeiras na governança do dia a dia na Somália e considerando que a pirataria é um fenômeno altamente localizado, concentrado em algumas comunidades costeiras do litoral nordeste e central do país, são as necessidades de desenvolvimento e segurança em microescala das pessoas inseridas no contexto particular da pirataria somali e as intervenções dentro desse contexto particular que realmente condicionam as possibilidades concretas de transformação da economia política da pirataria somali e não as receitas utópicas e virtuais baseadas em projetos externamente controlados de construção de um Estado central na Somália e, muito menos, as medidas de força orquestradas pelo CSNU desde 2008.

Ao olhar para essas iniciativas locais, e pensar na possibilidade de uma combinação equilibrada entre elas e os mecanismos internacionais de intervenção, é possível vislumbrar um novo horizonte de ação diplomática contra a pirataria que parece adequado e melhor dimensionado ao contexto particular da Somália. Em vez de estigmatizar os atores e as instituições costumeiras locais como instâncias antidemocráticas, corruptas, ineficientes e primitivas e, devido a essas qualidades, prejudiciais aos esforços internacionais de construção da paz, o caminho mais produtivo parece ser, seguindo as indicações de Richmond e Mitchell (2012, p. 13, 23), valorizar a capacidade que esses agentes e instituições locais têm de contribuir para os esforços da governança global, fazendo emergir uma nova abordagem - "híbrida" segundo o rótulo atribuído pelos dois autores - que torne os esforços internacionais de construção da paz mais pluralistas, criativos, contextualizados, enraizados nas necessidades do dia a dia das comunidades locais e, consequentemente, mais sustentáveis a longo prazo.

É importante notar, porém, que a valorização das formas de agência local, das suas afirmações de autonomia, do tipo de política informal que provê grande parte da governança do dia a dia e das interações de aceitação e rejeição que surgem nesse espaço híbrido de ação local-internacional, não implica a construção de algo novo a partir do zero ou no descarte absoluto do projeto liberal de construção da paz. A questão levantada por Richmond, Mitchell e seus colaboradores (2012) não está propriamente centrada numa rejeição absoluta das capacidades e dos conhecimentos acumulados dentro do projeto da paz liberal per se, mas sim na forma como essa bagagem acumulada tem sido instrumentalizada e imposta como um mecanismo padronizado de governança global que ignora as reais necessidades de segurança e desenvolvimento do contexto local, negligencia as formas costumeiras de autoridade e governo e sufoca qualquer possibilidade de resistência surgida no dia a dia das comunidades locais (BLEIKER, 2012, p. 305). Desse modo, o que esses autores propõem, de fato, é um ajuste, uma correção de rumo nesse projeto dominante que se tem desconectado do dia a dia das sociedades-alvo de intervenção e produzido uma "paz alienada" (MITCHELL, 2010), cada vez mais determinada por uma lógica robusta de pacificação difícil de ser assimilada dentro da esfera comunitária local. 
Ao desconectar-se do quotidiano das comunidades em prol de um projeto de engenharia social externamente controlado de inspiração liberal, fortemente sustentado num aparato de segurança, o projeto transformativo da paz liberal acaba criando uma situação paradoxal na qual os interventores se veem obrigados a traduzir os seus princípios emancipatórios através de formas coercivas e autoritárias de governança, a fim de controlar as manifestações violentas de oposição local. Dentro desse processo - onde formas violentas de resistência local e reações robustas e coercivas dos interventores se sucedem num círculo vicioso que tende a aumentar a instabilidade em vez de a mitigar (RICHMOND e MITCHELL, 2012, p. 4) - a paz liberal torna-se uma espécie de "guerra liberal", um mecanismo de segurança através do qual os propósitos emancipatórios da paz são impostos a qualquer custo, mesmo que para isso seja preciso matar aqueles que esse projeto ideológico pretende emancipar (DILLON e REID, 2009).

Os arranjos da governança global da pirataria - concentrados num conjunto de práticas diplomáticas regulatórias e justificatórias das ações estatais, numa mobilização internacional robusta de natureza preponderantemente coerciva e num projeto de construção do Estado central na Somália sem grande legitimidade e sustentação interna, principalmente nas zonas remotas e esquecidas onde proliferam as bases da pirataria - acabam incorrendo no paradoxo anteriormente mencionado. Se é importante desfazer esse paradoxo, de tal modo que os esforços internacionais não se reduzam a um mero dispositif de segurança (OLIVEIRA, 2013a, p. 12-13), a abordagem híbrida aqui referida parece indicar uma alternativa positiva. Ao focar na interface local-internacional, defendendo formas de atuação mais sensiveis ao contexto e atentas às atividades, necessidades, interesses, cultura, formas costumeiras de autoridade e governo e experiências do dia a dia das populações locais, sem contudo dispensar as capacidades, recursos e conhecimentos acumulados pelos mecanismos de intervenção internacional, a abordagem híbrida à pirataria vislumbra novas possibilidades de ação diplomática através das quais a governança da segurança marítima pode ser pensada e realizada de uma forma mais holística, transformadora e emancipatória.

Dadas as características próprias das instâncias costumeiras de autoridade e governança locais e a lógica de pragmatismo e sobrevivência que tem regido a interface local-internacional na Somália nos últimos vinte anos - fazendo com que objetivos importantes do ponto de vista internacional tendam a ser realizados somente quando os próprios somalis os incorporam dentro dos seus quadros de entendimento e os percebem como meios úteis para atingir fins e prioridades de suas agendas locais (SANDSTROM 2012, p. 140) - a realização do potencial contido na abordagem híbrida à pirataria aqui sugerida depende de um compromisso autêntico das esferas internacionais com a transformação social dentro do contexto mais próximo da pirataria somali. É crucial, portanto, que os incentivos externos atendam de fato às necessidades concretas de desenvolvimento próprias das comunidades dependentes da pirataria e deixem de ser canalizados através de intervenções securitizadas e de projetos virtuais de engenharia social. Ao olhar para o conflito persistente na Somália, não se deve esquecer que intervenções coercivas e ações autointeressadas de atores externos só têm contribuído para reduzir a permeabilidade da sociedade somali à penetração dos esforços internacionais e para alimentar resistências internas violentas. 


\section{Conclusão}

A abordagem híbrida à pirataria proposta neste artigo sugere uma via diplomática alternativa para lidar com o problema, construída na interface local-internacional, enraizada no contexto concreto que envolve a pirataria somali e centrada nas possibilidades de interação entre as esferas oficiais e não oficiais de ação. Com essas características, essa abordagem conecta-se ao debate sobre a necessidade de novas formas de ação diplomática neste mundo em mudança, procurando destacar o contexto particular dos conflitos prolongados e intratáveis, onde as capacidades operacionais formais do Estado praticamente se dissolvem e fazem emergir mecanismos informais e costumeiros que conseguem dar à governança do dia a dia algum grau de estabilidade. 0 caso da Somália é exemplar nesse sentido e o problema da pirataria consegue ilustrar, de uma forma emblemática, as dificuldades de se lidar, através de mecanismos exclusivamente formais e oficiais, com uma questão essencialmente privada, surgida no contexto de uma sociedade fragmentada e sem um governo central efetivo há quase três décadas (apesar dos esforços internacionais no sentido de fortalecer e consolidar o embrião do Governo Federal da Somália). Num contexto desse tipo, onde praticamente inexistem interlocutores "oficiais" capazes de atender, dentro dos mínimos padrões de efetividade, os requisitos exigidos pela diplomacia convencional, não há como ignorar as potencialidades das instâncias governativas locais e as possibilidades do seu envolvimento na solução de problemas que afetam diretamente o seu dia a dia.

\section{Referências}

ABBINK, Jan. 2009. The Total Somali Clan Genealogy. Leiden: African Studies Centre.

ADAN, Hussein M. 2010. Political Islan in Somali History. In HOEHNE, Markus e LULING, Virginia (eds.) Milk and Peace, Drought and War: Somali Culture, Society and Politics. London: Hurst \& Company, p. 117-136.

AZAR, Edward. 1985. Protracted International Conflict: Ten Propositions. International Interactions, v. 12, n. 1, p. 59-70.

AZAR, Edward. 1990. The Management of Protracted Social Conflict: Theory \& Cases. Aldershot: Dartmouth. AZAR, Edward. 2003. Protracted Social Conflicts and Second Track Diplomacy. In DAVIES, J. e KAUFMAN, E. (eds.) Second Track/ Citizens' Diplomacy: Concepts and Techniques for Conflict Transformation. Oxford: Rowman \& Littlefield, p. 15-30.

BALLENTINE, Karen e SHERMAN, Jake. 2003. The political Economy of Armed Conflict: beyond greed and grievance. London: Lynne Rienner.

BERDAL, Mats e MALONE, David M. (eds.). 2000. Greed and Grievance: economic agendas in civil wars. Boulder: Lynne Rienner.

BLEIKER, Roland. 2012. Conclusion - Everyday Struggles for a Hybrid Peace. In RICHMOND, Oliver e MITCHELL, Audra (eds.) Hybrid Forms of Peace: From Everyday Agency to Post-Liberalism. Basingstoke: Palgrave Macmillan, p. 293-308. 
BUEGER, Christian e STOCKBRUEGGER, Jan. 2013. Security Communities, Alliances, and Macrosecuritization: The Practice of Counter-Piracy Governance. In STRUET, Michael J., CARLSON, Jon D. e NANCE, Mark T. (eds.) Maritime Piracy and the Construction of Global Governance. Abingdon: Routledge, p. 99-124.

CASSANELLI, Lee V. 2010. Speculations on the Historical Origins of the 'Total Somali Genealogy'. In HOEHNE, Markus e LULING, Virginia (eds.) Milk and Peace, Drought and War: Somali Culture, Society and Politics. London: Hurst \& Company, p. 51-66.

COHEN, Stephan P. e AZAR, Edward. 1981. From War to Peace: The Transition between Egypt and Israel. Journal of Conflict Resolution, v. 25, n. 1, p. 87-114.

COLlier, Paul e HOEFFLeR, Anke. 1998. On Economic Causes of Civil War. Oxford Economic Papers, v. 50 , p. 563-573.

COLLIER, Paul. 2000. Doing Well out of War: an economic perspective. In BERDAL, Mats e MALONE, David M. (eds.) Greed and Grievance: economic agendas in civil wars. Boulder: Lynne Rienner, p. 91-111.

DIAMOND, Louise e MCDONALD, John W. 1996. Multi-track diplomacy: a systems approach to peace. West Hartford: Kumarian Press.

DILLON, Michael e REID, Julian. 2009. The Liberal way of War: Killing to make Life Live. London: Routledge.

DUFFIELD, Mark. 2000. Globalization, Transborder Trade, and war Economies. In Mats BERDAL, Mats e MALONE, David M. (eds.) Greed and Grievance: Economic Agendas in Civil Wars. Boulder: Lynne Rienner, p. 69-89.

DUFFIELD, Mark. 2001. Global Governance and the New Wars: The Merging of Development and Security. London: Zed Books.

DUFFIELD, Mark. 2007. Development, Security and Unending War: Governing the World of Peoples. Cambridge: Polity Press.

EICHSTAEDT, Peter. 2010. Pirate State: Inside Somalia's Terrorism at Sea. Chicago: Lawrence Hill Books.

ELMI, Afyare Abdi. 2010. Understanding the Somalia Conflagration: Identity, Political Islam and Peacebuilding. London: Pluto Press.

HANSEN, Stig Jarle. 2009. Piracy in the greater Gulf of Aden: Myths, Misconceptions and Remedies. Norwegian Institute for Urban and Regional Research: NIBR Report 2009:29.

HAYWOOD, Robert e SPIVAK, Roberta. 2012. Maritime Piracy. Abingdon: Routledge.

HEINZE, Eric A. 2013. A 'Clobal War on Piracy?'. In STRUETT, Michael J., CARLSON, Jon D. e NANCE, Mark T. (eds.) Maritime Piracy and the Construction of Global Governance. London: Routledge, p. 54-55.

HOMAN, Kees e KAMERLING, Susanne. 2010. Operational Challenges to Counterpiracy Operations off the Coast of Somalia. In GINKEL, Bibi e PUTTEN, Frans-Paul (eds.) Response to Somali Piracy: Challenges and opportunities. Leiden: Martinus Nijhoff Publishers, p. 65-103.

KALDOR, Mary. 1999. New and Old Wars: organized violence in a global era. Cambridge: Polity Press.

KEEN, David. 1998. The economic functions of violence in civil wars. Oxford: Oxford University Press.

KEEN, David. 2000. Incentives and desincentives for violence. In BERDAL, Mats e MALONE, David M. (eds.) Greed and grievance: economic Agendas in Civil Wars. Boulder: Lynne Rienner, p. 19-41. 
KILCULLEN, David. 2010. Counterinsurgency. Oxford: Oxford University press.

KRIESBERG L., TERRELL, T. A. e NORTHRUP, S. J. (eds.). 1989. Intractable Conflicts and Their Transformation. Syracuse: Syracuse University Press.

KUMAR, R. 1987. Theories of Conflict Resolution and Their Applicability to Protracted Ethnic Conflicts. Security Dialogue, v. 18, n. 4, p. 527-539.

LEDERACH, J. Paul. 1997. Preparing for Peace: Conflict Transformation across Cultures. Washington, D.C.: United States Institute of Peace Press.

LITTLE, Peter D. 2003. Somalia: Economy without State. Bloomington: Indiana University Press.

MENKHAUS, Ken. 2002. Political Islan in Somalia. Middle East Policy, v. 9, n. 1, p. 109-123.

MENKHAUS, Ken. 2010. The Question of Ehnicity in Somali Studies. In HOEHNE, Markus e LULING, Virginia (eds.) Milk and Peace, Drought and War: Somali Culture, Society and Politics. London: Hurst \& Company, p. 87-104.

MITCHELL, Audra. 2010. Peace beyond Process? Milleniun Journal of International Studies, v. 38, n. 3, p. 641-665.

MONTVILLE, J. V. 1991. The Arrow and the Olive Branch: A Case for Track Two Diplomacy. In VOLKAN, V. D., MONTVILLE, J. V. e JULIUS, D. A. (eds.) The Psychodynamics of International Relationships. Massachusetts: Lexington Books, p. 161-175.

MURPHY, Martin N. 2011. Somalia: The New Barbary? Piracy and Islam in the Horn of Africa. London: Hurst \& Company.

OLIVEIRA, Gilberto C. 2013a. "New Wars" at Sea: A Critical Transformative Approach to the Political Economy of Somali Piracy. Security Dialogue, v. 44, n. 1, p. 3-18.

OLIVEIRA, Gilberto C. 2013b. A interface interna-externa da segurança no espaço oceânico: o caso da criminalidade marítima. Relações Internacionais, n. 40, p. 31-50.

OLIVEIRA, Gilberto C. 2015. Securitização da violência privada no mar: a construção da pirataria somali como problema de segurança internacional. In BARRINHA, A. e FREIRE, M. R. (eds.) Segurança, Liberdade e Política: Pensar a Escola de Copenhaga em Português. Lisboa: Imprensa de Ciências Sociais, p. 107-139.

PELTON, Robert Y. 2012. Puntland Marine Police Force Enter Eyl. Somalia Report. 3 fev. 2012. Disponível em: [ http://www.somaliareport.com/index.php/post/2978 ]. Acesso em: 7 jun. 2011.

PHAM, Peter J. 2011. Somalia: Where a State Isn't a State. The Fletcher Forum of World Affairs, v. 35, n. 2, p. 133-151.

PUCH, Michael e COOPER, Neil. 2004. War economies in a regional context: challenges of transformation. London: Lynne Rienner.

RENO, William. 1999. Warlord Politics and African States. Boulder: Lynne Rienner.

RENO, William. 2000. Shadow States and the political economy of civil wars. In BERDAL, Mats e MALONE, David M. (eds.) Greed and Grievance: Economic Agendas in Civil Wars. Boulder: Lynne Rienner, p. 43-68.

RENO, William. 2003. Somalia and Survival in the Shadow of the Global Economy. Queen Elizabeth House Working Paper Number 100, Oxford: Oxford University Press. 
RICHMOND, Oliver P. e AUDRA, Mitchell (eds.). 2012. Hybrid Forms of Peace: From Everyday Agency to Post-Liberalism. Basingstoke: Palgrave.

SANDSTROM, Karl. 2012. Cooptation, Acceptance and Resistance in the Somali 'Everyday'. In RICHMOND, Oliver e AUDRA, Mitchell (eds.) Hybrid Forms of Peace: From Everyday Agency to Post-Liberalism. Basingstoke: Palgrave Macmillan, p. 131-144.

SOMALIA REPORT. 2012. What is Bandar Beyla? Somalia Report, 5 Jun. 2012. Disponivel em: [http://somaliareport.com/index.php/post/3419/What_is_Bandar_Beyla]. Acesso em: 5 de Jun. 2012.

S/RES/1846/2008 UN Security Council Resolution 1846 (2008). New York: United Nations.

S/RES/1897/2009 UN Security Council Resolution 1897 (2009). New York: United Nations.

WALJE, Matt. 2013. Community Mobilization and Criminal Organizations: Eyl, Somalia. Broomfield: Oceans Beyond Piracy. 